\section{Empirical assessment of colour symmetries}

\author{
Lewis D. Griffin \\ Department of Optometry and Vision Sciences, Ashton University, \\ Birmingham B4 7ET, England. I.d.griffin@aston.ac.uk \\ www.vs.aston.ac.uk/staff/lgriffin.html
}

Abstract: The quality of potential symmetries of the similarity structure of the Basic Colour Terms has been assessed. The assessment was made on the basis of a database of similarity judgements, made by subjects in response to linguistically expressed questions. All potential symmetries can be statistically rejected, although the well-known and some novel interpretable symmetries are shown to be approximately correct.

To investigate possible symmetries of the colours, a database of colour similarity judgements was amassed using questionnaires. Each questionnaire consisted of 200 questions of the form "which is the more similar pair A and B or C and D?" where A-D were randomly drawn from the 11 Basic Colour Terms (BCTs). The questions were linguistic; no colour samples were used. Only subjects who assessed themselves as having normal colour vision and spoke English as their main language were used.

A total of 47,557 responses were collected from 194 subjects. Ignoring the order of colours within a pair and the ordering of the two pairs, there are 1,485 possible questions. So on average, each question had 32.0 responses. The questions elicited varying levels of agreement. For example, 33 versus 3 choose Purple and Black as more similar than Green and Black, whereas subjects split 17 versus 17 over Green and Red versus Brown and White. If agreement rate is defined so that it is $91.7 \%$ and $50.0 \%$, respectively, for the previous two examples, the average agreement rate across all questions was $79.1 \%$.

To appreciate what a symmetry within the database of responses would amount to, imagine data being collected in the fol- lowing manner. Suppose questions are asked in the form "A and $\mathrm{B}$ or $\mathrm{C}$ and $\mathrm{D}$ ?" and each questionnaire is accompanied by a key translating letters into BCTs. The existence of a symmetry could be investigated by having two cohorts of subjects complete questionnaires, with each cohort using a different key. If the judgements of the two cohorts were found to be statistically distinguishable, the proposed symmetry, encoded in the relation between the two keys, would be rejected. Fortunately, given the number of potential symmetries, this clumsy method of data collection is unnecessary; the assessment can be made by comparing the response database to a transformed version of itself.

To describe how potential symmetries are assessed, consider a concrete example: the swapping of Red and Orange, Yellow and Pink, and Purple and Brown. First, each of the 1,485 questions is assessed for whether it is affected by the permutation of colours. A question such as "Red and Yellow or Pink and Blue" is affected, whereas "Red and Orange or Blue and Grey" is not. Next, consider an affected question such as "Purple and Orange or Yellow and Green." This had response 4 versus 26. After permutation of colours, the question becomes "Brown and Red or Pink and Green," which had response 32 versus $0 . \chi^{2}$ tests are then used to measure the discrepancy, in a weak and in a strong sense, between the two response patterns. The strong measure is the score from a $\chi^{2}$ test that the response patterns are identical; the weak measure is the score from a $\chi^{2}$ test of the hypothesis that the majority answer is the same in both cases. The weak and the strong $\chi^{2}$ scores for all the affected questions are separately summed to give overall scores for the symmetry. Because different symmetries affect different numbers of questions, the $X^{2}$ scores of different symmetries have different numbers of degrees-of-freedom $(v)$ and so cannot be directly compared. To allow comparison, $\chi^{2}$ scores are normalised according to

$$
S d s=\frac{\chi^{2}-v}{\sqrt{2 v}}
$$

this is valid given the size of $v$. A Sds (standard deviations) value greater than 1.64 is evidence that a proposed symmetry should be rejected.

Table 1 shows the 5 best symmetries of the Hering primaries and Table 2 shows a selection of symmetries of all 11 BCTs. Both tables are ordered by the size of the weak $\mathrm{Sds}$ measure. The tables also show for each symmetry the question most violated by the responses. The remaining column, "fractional agreement," allows the quality of the symmetry to be assessed. It is calculated as the expected rate of agreement between two subjects using different keys (related by the symmetry), as a fraction of the expected rate if they use the same key. As can be seen from the Sd score in both tables all symmetries can be rejected. However, the fractional agreement scores show that there are several good approximate symmetries. Some of these are interpretable in relation to the standard octahedron model of colour space.

The best symmetry for the Hering primaries can be pictured as a $180^{\circ}$ rotation about the Red-Green axis. As shown by the "worst question" for this symmetry, its main flaw lies in the mapping of Blue-White to Yellow-Black. The second best symmetry is a reflection in the Black-White-Yellow-Blue plane. Its main flaw is the mapping of Blue-Red to Blue-Green. The next two symmetries do not preserve the topology of the colour octahedron. The fifth symmetry is the best that transforms all six colours. It is the composition of the first two symmetries, but can also be understood as a mapping of the primaries to their complements.

The best 9 symmetries of the 11 BCTs clearly violate the topology of the BCTs, for example, the first maps Blue-White to BlackWhite. They have good fractional agreements, however, in particular the third, which has the highest of all the potential symmetries. The best symmetry that is reasonably in accord with topology is the 10th, which corresponds to a one-step rotation of the hue circle. Perhaps its worst violation of topology is the mapping from Blue-Brown (not adjacent) to Purple-Brown (adjacent). The next topologically reasonable symmetry is the 12 th, which can 
Commentary/Palmer: Color and consciousness

Table 1 (Griffin). The 5 best symmetries (out of 397) of the 6 Hering primaries

\begin{tabular}{|c|c|c|c|c|c|}
\hline $\begin{array}{l}\text { Symmetry } \\
\text { number }\end{array}$ & Symmetry & $\begin{array}{l}\text { Weak } \\
\text { Sds }\end{array}$ & $\begin{array}{l}\text { Strong } \\
\text { Sds }\end{array}$ & $\begin{array}{l}\text { Fractional } \\
\text { Agreement }\end{array}$ & Worst Question \\
\hline 1 & Yellow $\leftrightarrow$ Blue, Black $\leftrightarrow$ White & 7.3 & 25.9 & $91.7 \%$ & $\begin{array}{l}\mathrm{Y} \& \mathrm{~B}(4) \text { vs. } \mathrm{Bl} \& \mathrm{~W}(30) \\
\mathrm{Bl} \& \mathrm{~W}(30) \text { vs. Y \& B (4) }\end{array}$ \\
\hline 2 & Red $\leftrightarrow$ Green & 9.7 & 26.8 & $89.7 \%$ & $\begin{array}{l}\mathrm{Bl} \& \mathrm{G}(26) \text { vs. } \mathrm{Bl} \& \mathrm{R}(4) \\
\mathrm{Bl} \& \mathrm{R}(4) \text { vs. } \mathrm{Bl} \& \mathrm{G}(26)\end{array}$ \\
\hline 3 & $\begin{array}{l}\rightarrow \text { Red } \rightarrow \text { Blue } \rightarrow \text { Yellow } \rightarrow \\
\text { Black } \rightarrow \text { White } \rightarrow\end{array}$ & 11.6 & 42.7 & $87.1 \%$ & $\begin{array}{l}\text { Y \& G (22) vs. } \mathrm{G} \& \mathrm{R}(8) \\
\mathrm{B} \& \mathrm{G}(5) \text { vs. } \mathrm{G} \& \mathrm{Bl}(26)\end{array}$ \\
\hline 4 & Red $\leftrightarrow$ White & 11.9 & 31.2 & $89.1 \%$ & $\begin{array}{l}\mathrm{R} \& \mathrm{~B}(27) \text { vs. } \mathrm{W} \& \mathrm{~B}(3) \\
\mathrm{W} \& \mathrm{~B}(3) \text { vs. } \mathrm{R} \& \mathrm{~B}(27)\end{array}$ \\
\hline 5 & $\begin{array}{l}\text { Yellow } \leftrightarrow \text { Blue, } \\
\text { Black } \leftrightarrow \text { White, Red } \leftrightarrow \text { Green }\end{array}$ & 12.6 & 48.6 & $85.3 \%$ & $\begin{array}{l}\mathrm{Y} \& \mathrm{~B}(4) \text { vs. } \mathrm{Bl} \& \mathrm{~W}(30) \\
\mathrm{Bl} \& \mathrm{~W}(30) \text { vs. Y \& B (4) }\end{array}$ \\
\hline
\end{tabular}

Color code: $\mathrm{Y}=$ yellow; $\mathrm{B}=$ black; $\mathrm{Bl}=$ blue; $\mathrm{W}=$ white; $\mathrm{R}=$ red; $\mathrm{G}=$ green.

Table 2 (Griffin). A selection of the 19,976,247 potential symmetries of the BCTs

\begin{tabular}{|c|c|c|c|c|c|}
\hline $\begin{array}{l}\text { Symmetry } \\
\text { number }\end{array}$ & Symmetry & $\begin{array}{l}\text { Weak } \\
\text { Sds }\end{array}$ & $\begin{array}{l}\text { Strong } \\
\text { Sds }\end{array}$ & $\begin{array}{l}\text { Fractional } \\
\text { Agreement }\end{array}$ & Worst Question \\
\hline 1 & Black $\leftrightarrow$ Blue & 18.2 & 74.7 & $92.2 \%$ & $\begin{array}{l}\mathrm{Bl} \& \mathrm{~W}(29) \text { vs. W \& B (1) } \\
\mathrm{B} \& \mathrm{~W}(1) \text { vs. W \& Bl (29) }\end{array}$ \\
\hline 2 & Yellow $\leftrightarrow$ Orange & 23.5 & 92.1 & $89.8 \%$ & $\begin{array}{l}\mathrm{O} \& W(0) \text { vs. } Y \& W(30) \\
Y \& W(30) \text { vs. } O \& W(0)\end{array}$ \\
\hline 3 & $\begin{array}{l}\text { Red } \leftrightarrow \text { Orange, Y } \leftrightarrow \text { Pink, } \\
\text { Green } \leftrightarrow \text { Purple }\end{array}$ & 24.2 & 92.1 & $93.0 \%$ & $\begin{array}{l}\mathrm{Pu} \& \mathrm{~B}(33) \text { vs. G \& B (3) } \\
\mathrm{G} \& \mathrm{~B}(3) \text { vs. } \mathrm{Pu} \& \mathrm{~B}(33)\end{array}$ \\
\hline 10 & $\begin{array}{l}\rightarrow \text { Red } \rightarrow \text { Orange } \rightarrow \text { Yellow } \rightarrow \\
\text { Green } \rightarrow \text { Blue } \rightarrow \text { Purple } \rightarrow\end{array}$ & 30.8 & 109.6 & $90.8 \%$ & $\begin{array}{l}O \& W(0) \text { vs. } Y \& W(30) \\
Y \& W(33) \text { vs. } G \& W(1)\end{array}$ \\
\hline 12 & $\begin{array}{l}\text { Red } \leftrightarrow \mathrm{O}, \mathrm{Y} . \leftrightarrow \mathrm{Pu}, \mathrm{P} \leftrightarrow \mathrm{Br} \\
\text { Green } \leftrightarrow \text { Blue, Black } \leftrightarrow \mathrm{W}\end{array}$ & 32.3 & 103.6 & $91.4 \%$ & $\begin{array}{l}\mathrm{P} \& \mathrm{Bl}(4) \text { vs. } \mathrm{Br} \& \mathrm{G}(43) \\
\mathrm{Br} \& \mathrm{G}(43) \text { vs. } \mathrm{P} \& \mathrm{Bl}(4)\end{array}$ \\
\hline 19 & $\begin{array}{l}\mathrm{Y} \leftrightarrow \text { Blue, Black } \leftrightarrow \mathrm{W} \\
\text { Orange } \leftrightarrow \mathrm{Pu}, \text { Pink } \leftrightarrow \text { Brown }\end{array}$ & 35.9 & 113.8 & $90.6 \%$ & $\begin{array}{l}\text { P \& G (2) vs. Br \& Y (31) } \\
\text { Br \& G (43) vs. P \& Bl (4) }\end{array}$ \\
\hline 48 & $\begin{array}{l}\rightarrow \mathrm{R} \rightarrow \mathrm{Bl} \rightarrow \mathrm{Y} \rightarrow \mathrm{Br} \rightarrow \text { Grey } \rightarrow \mathrm{P} \\
\rightarrow \mathrm{Pu} \rightarrow \text { Green } \rightarrow \mathrm{O} \rightarrow \mathrm{B} \rightarrow \mathrm{W} \rightarrow\end{array}$ & 41.1 & 142.1 & $88.4 \%$ & $\begin{array}{l}\mathrm{Bl} \& \mathrm{Gr}(27) \text { vs. } \mathrm{Gr} \& \mathrm{~W}(1) \\
\mathrm{Y} \& \mathrm{P}(3) \text { vs. O \& R (30) }\end{array}$ \\
\hline
\end{tabular}

Color code: $\mathrm{Y}=$ yellow; $\mathrm{B}=$ black; $\mathrm{Bl}=$ blue; $\mathrm{W}=$ white $\mathrm{Pu}=$ purple; $\mathrm{R}=$ red; $\mathrm{G}=$ green; $\mathrm{O}=$ orange; $\mathrm{P}=$ pink; $\mathrm{Br}=$ brown; $\mathrm{Gr}=$ grey.

be understood as a $180^{\circ}$ rotation about an axis through Red/Orange-Grey-Blue/Green. I am unaware of any previous mention of this approximate symmetry. The 19th symmetry is rotation about an axis through Red-Grey-Green: This is the first symmetry of Table 1. The 48th symmetry is the best that transforms all 11 BCTs. It neatly maps Black-Grey-White to White-Pink-Red, Red-Pink-White to Blue-Purple-Red, Orange-Brown Black to Black-Grey-White, and Red-Orange-Yellow-Green-Blue-Purple to Blue-Black-Brown-Orange-Yellow-Green. 